\title{
Goal Model to Business Process Model: A Methodology for Enterprise Government Tourism System Development
}

\author{
Ahmad Nurul Fajar ${ }^{1}$, Imam Marzuki Shofi ${ }^{2}$ \\ ${ }^{1}$ Departement of Master of Information System, Bina Nusantara University, Jakarta, Indonesia \\ ${ }^{2}$ Departement of Informatics Engineering, UIN Syarif Hidayatullah Jakarta, Indonesia
}

\begin{tabular}{l} 
Article Info \\
\hline Article history: \\
Received Jun 10, 2016 \\
Revised Sep 21, 2016 \\
Accepted Oct 5, 2016 \\
\hline
\end{tabular}

Keyword:

Business process model (BPM)

Enterprise government tourism system

Goal model

Requirement analysis

\begin{abstract}
The critcal factor in successfully in system development is the requirement phase. The requirement should meets with its purpose. In order to achieve it, the methodology for requrement analysis is needed. Nowdays, the complexity of e-governemnt applications is grown significantly in the government environment. E-government applications should be developed based on regulations in order to achieve the goal model of government entitties. However, the goal model could not used directly to make business process model. In order to solve this problem,this paper presents and proposed a Methodology to extract goal model into business process model that called GBPM Methodology. It can support the requirement analysis phase, especially in enterprise government tourism system. This methodology consists of two methods, there are (1) Method for convert goal model to business use case diagram, (2) Method for convert business use case diagram to activity diagram. We do the experiment in e-government applications domain. This methodology suitable with enterprise government tourism system development.
\end{abstract}

Copyright $\odot 2016$ Institute of Advanced Engineering and Science. All rights reserved.

\section{Corresponding Author:}

Ahmad Nurul Fajar,

Binus Graduate Program,

Bina Nusantara University,

Kebun Jeruk Raya Street, Jakarta, Indonesia.

Email: afajar@binus.edu, ahmadnurulfajar@gmail.com

\section{INTRODUCTION}

Requirement Analysis is the phase in Requirements Engineering (RE).It focused on how to exploration of the user and system needed .The measurement of the success of the implementation software system is the degree to which it meets its purpose Requirement Engineerng (RE) is the process of discovering that purpose, by identifying stakeholders and their needs [1]. This process also documenting these in a form which is for analysis, communication, and subsequent implementation [1].

Goal and Actor orientation has been recognized as an approach more promising than functionality based techniques used in most of the traditional Software Engineering methodologies [2]. The approach of RE based on Goal and Actor orientation. This approach increase dramatically which is called Goal Oriented Requirement Engineering (GORE). In order to solve problem in complex software system, we can use GORE approach, because of the inadequacy of the traditional systems analysis when dealing with more and more complex software systems [3]. Business Process Model (BPM) is a concept which able to use for a wide variety of situations and also for many goal. Business process models are a crucial prerequisite for business processes analysis, representation goal and objectives, and also finding the information structures better in the form of a compound of distributed, integrated systems which support structure organization [4-6].

Complexity of e-government applications is grown significantly in the government environment. It causes a continue unpredictable changing in government regulations. In order to response to the change, 
providing variant of business processes are a challenge. The challenges are how to identified and manage the commonality and variability business processes. The identification variability patterns involving activities within processes sharing a significant amount of similarity [7].

\section{RESEARCH METHOD}

RE concern about the needs to discover, understand, formulate, analyze and agree on what problem what should be solved, why such a problem needs to be solved, and who should be involved in the responsibility of solving that problems [8]. According to [8], there are three dimensions in RE, such as why, what, and who.

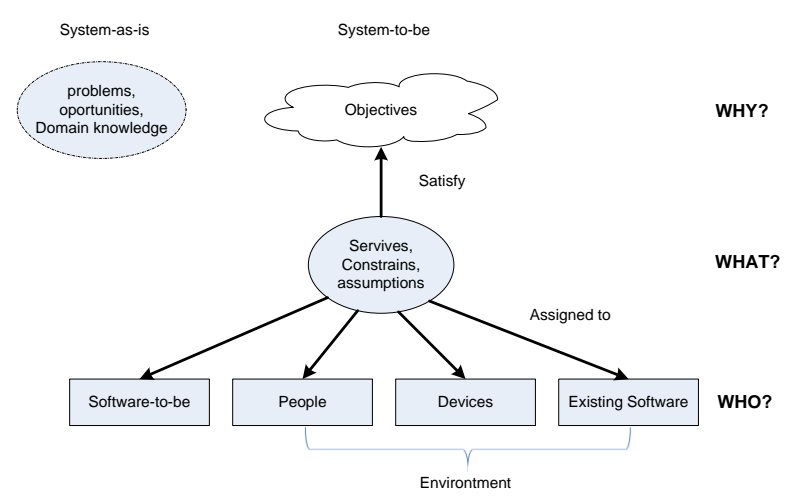

Figure 1. Three Dimensions of Requirements Engineering [8]

According to Martin Schedlbauer [4] Business Process Modelling are the set of activity for eliciting, documenting, visualizing, and analysing work procedures within an organization. According to Champ and Hammer, a business process is "a collection of activities that takes one or more kinds of input and creates an output that is of value to the customer". A business process model captures the activities an organization has to perform to achieve a particular business goal [9-10]. A base process can be adjusted in different ways to configure a specific process variant [10]. Business process modelling tools provide business users with the ability to model their business processes, implement and execute those models, and refine the models based on as - executed data [11-12]. As a result, business process modelling tools can provide transparency into business processes, as well as the centralization of corporate business process models and execution metrics [11-12].

\section{RESULTS AND ANALYSIS}

According to background and state of the art, we proposed A methodology in RE which is focused on requirement analysis. Visualization and the steps of the GBPM methodology can be seen in Figure 2 below. The Figure 2 below consists of two methods, there are: (1) Method for convert goal model to business use case diagram, (2) Method for convert business use case diagram to activity diagram.

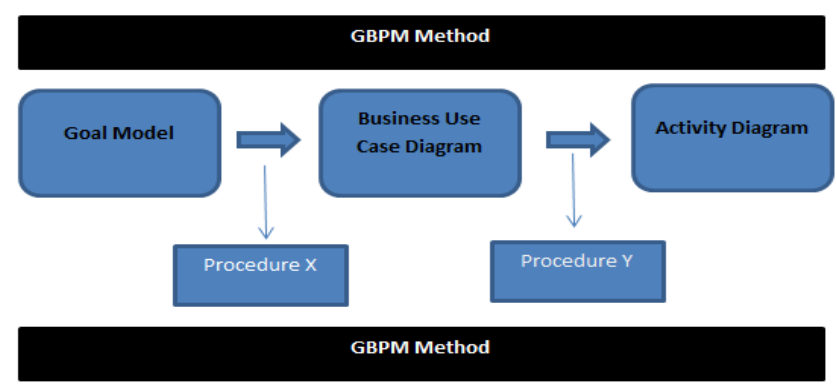

Figure 2. The Steps of GBPM Methodology 
According to Figure 2, there are 2 methods for convert goal model to activity diagram. Figure 3 below explain about procedure X, which is called Method for convert goal model to business use case diagram, and Figure 4 explain about procedure $\mathrm{Y}$, which is called Method for convert business use case diagram to activity diagram.

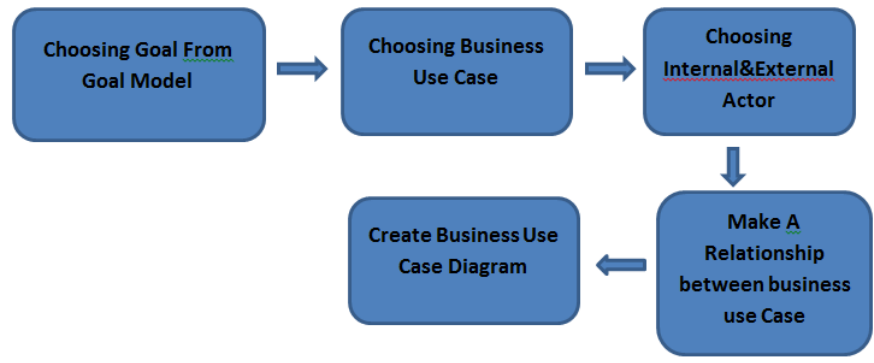

Figure 3. Method for Convert Goal Model to Business Use Case Diagram

According to Figure 3 above, the method has five steps, there are: (1) Choosing goal from goal model, (2) Choosing business use case, (3) Choosing internal and External Actor, (4) Make a relationship between business use case, and (5) Create business use case diagram.

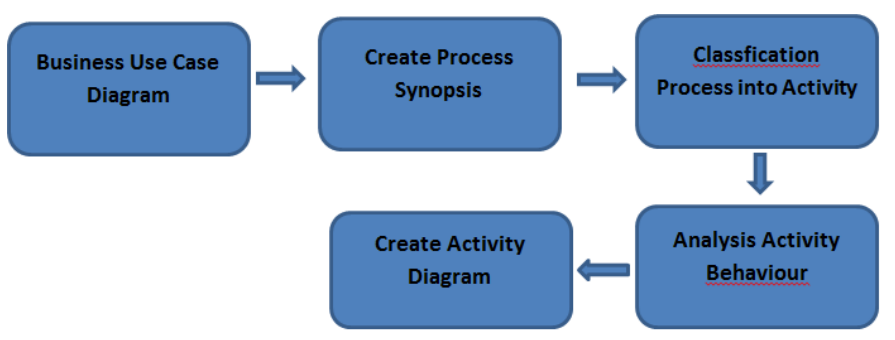

Figure 4. Method for Convert Business Use Case Diagram to Activity Diagram

According to Figure 4 above, the method has five steps, there are: (1) Business use case analysis, (2) Create process synopsis, (3) Classification Process into Activity, (4) Analysis Activity Behaviour, and (5) Create Activity diagram. In this method, we need a business use case diagram as an input, and the activity diagram as an output. The first step are analysing of business use case, the output of this step are process synopsis. In order to represent process synopsis, we use the template of process synopsis in the Table 1 below:

Table 1. Process Synopsis Template

\begin{tabular}{cccc}
\hline $\begin{array}{c}\text { Business Use } \\
\text { Case }\end{array}$ & $\begin{array}{c}\text { Internal } \\
\text { Actor }\end{array}$ & $\begin{array}{c}\text { External } \\
\text { Actor }\end{array}$ & Relationship \\
\hline$\ldots \ldots$ & $\ldots \ldots \ldots \ldots \ldots$ & $\ldots \ldots \ldots \ldots$ & $\ldots \ldots \ldots \ldots \ldots \ldots$ \\
\hline
\end{tabular}

We do the experiment for implement GBPM methodology in e-government application domain. We choose Indonesian Government system for experimental object. The conceptual thinking are because Government as a service provider should be aware that information is an asset and it must be managed properly. A better information management means a better service for the citizens and customized service to meet personal needs, and greater participation to determine what, how, and when service is provided. Indonesia has central government and local government. Local government consists of 33 provinces and 497 districts, which has common as well as specific business processes, policies, and rules [13].

These conceptual methodology would be implemented in Indonesian e-government applications. This environment has characteristics of features commonality and variability [12], [14].The definition of Features commonality means here are common. Then, the definition of features variability means 
specific [12], [14]. The conceptual methodology are suitable for the characteristics Indonesian government system or similar with it described in Figure 5 below. Figure 5 below described the local context of Indonesian government system that has local government and central government policy. Beside that, Central government has ministry and non ministry application, then the Local government has application in province, district, and agency. The characteristic of the application is has commonality and specificity features of application [12], [14]. According to empirical study, both of central and local government policy should base on document regulations. The government document regulations describe the thematic, objectives and rules. The document consists of dependency and independent of rules. The document also consists of constraints among the level in the hierarchy government policies. There are M...N relation between theme, rules and objective. Then, based on theme and objective, it representation rules.

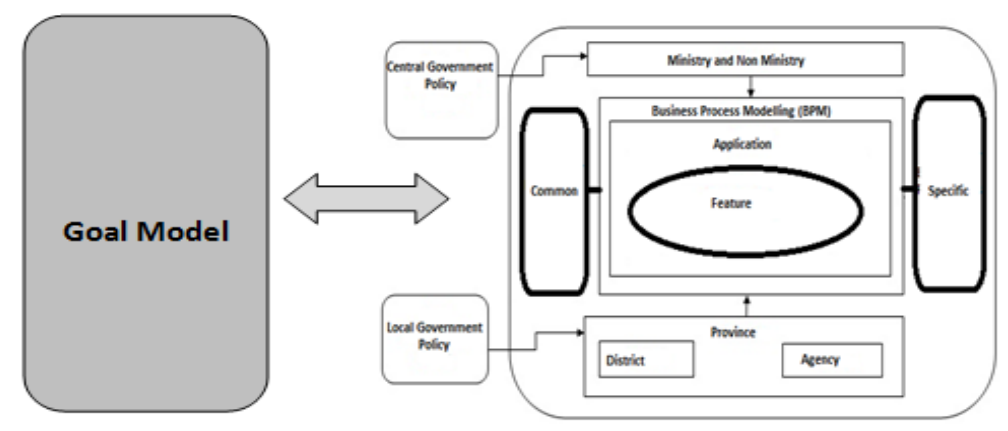

Figure 5. Goal Model and BPM Alignment [15]

According to the proposed conceptual methodology, we make a stage for experiment and verification / validation.We will make a workshop, and then the objects of experiment are related domain applications and their document regulations that related. We arranged workshop for 50 students which is consists of 10 groups. In this experiment we use Goal Model of budgeting application which is called Laksana, we use GBPM Methodology to convert Goal Model to Business Process Model. According to GBPM Method, which is consists of two methods,the results of mapping from goal model to high level business process model are represent in Table 2 below:

Table 2. Mapping from goal model to high level business process model

\begin{tabular}{lll}
\hline \multicolumn{1}{c}{ Goal } & \multicolumn{1}{c}{ Business Use Case } & \multicolumn{1}{c}{ Activity } \\
\hline Program \& Bugget managed & $\begin{array}{l}\text { Program managed \& Bugget } \\
\text { managed }\end{array}$ & $\begin{array}{l}\text { Bugget Planned } \\
\text { Bugget Realized } \\
\text { Bugget Monitored } \\
\text { Bugget Evaluated }\end{array}$ \\
& Annual Bugget Planning & $\begin{array}{l}\text { Created From Scratch } \\
\text { Bugget Planned }\end{array}$ \\
& $\begin{array}{l}\text { Created \& Annual Bugget } \\
\text { Planning Revised }\end{array}$ & $\begin{array}{l}\text { Created Using Template } \\
\text { Copied From Previous }\end{array}$ \\
& Migrated From Excel Format & Standard Excel Format Provided \\
Migrated From Existing Format File & File \& Migrated From Other & Standard Excel Format Read \\
& Format File & Standard Excel Format Converted \\
\hline
\end{tabular}

Government system Platform, shoud be developed with services based in business processes [16], and aware for security also [17]. According to our proposed methodology, we would like to implement the methodology in platform which is Figure 6. This platform are services based and suitable with government system. The platform described in Figure 6.

The Figure 6 described the platform enterprise government tourism system that consists of: (1) Merchant, (2) Payment Gateway System, (3) Culinary System, (4) Object Tourism System, (5) Transportation System, (6) Hotel System, (7) Integration System, and (8) User Multiple Access System. This Figure are explain mechanism of integration in many system in government tourism area. This platform can facilitate many entities to make business to business. 


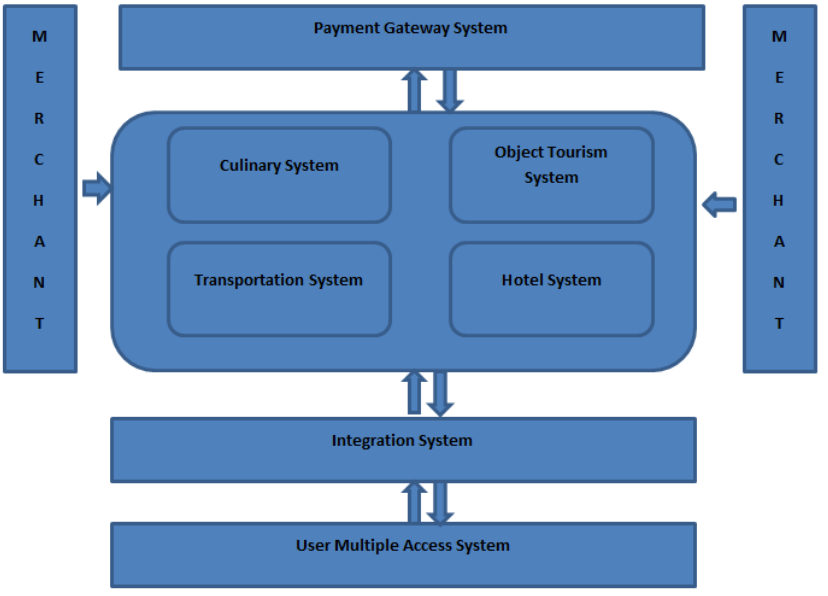

Figure 6. Enterprise Government Tourism System Platform

\section{CONCLUSION}

Requirement Analysis is the most significant phase in Requirement engineering for software development succesfully. In order to gathering requirement fit with its purpose, especially in egovernment environment, we proposed GBPM Methodology to extract goal mode into business proces model.This methodology consists of two method,the first method convert goal model to business use case diagram, and the second method convert business use case diagram to activity diagram. According to our proposed methodology, we would like to implement the methodology in platform that consists of: (1) Merchant, (2) Payment Gateway System, (3) Culinary System, (4) Object Tourism System, (5) Transportation System, (6) Hotel System, (7) Integration System, and (8) User Multiple Access System. This Figure are explain mechanism of integration in many system in government tourism area. This platform can facilitate many entities to make business to business.

\section{ACKNOWLEDGEMENTS}

This work was supported by to Professor Zainal A Hasibuan and Dr. Eko K Budiardjo at Faculty of Computer Science University of Indonesia.

\section{REFERENCES}

[1] B. Nuseibeh and S. Easterbrook, "Requirements Engineering: A Roadmap," Proc. Conference on the Future of Software Engineering.Limerick, Ireland, 2000.

[2] P. Donzelli and P. Bresciani, "Goal Oriented requirements Engineering: a case Study in eGovernment," Proceedings of the 15th Conference on Advanced Information Systems Engineering (CAISE'03), Klagenfurt, Austria, 16-20 June, 2003.

[3] A. Lapouchnian, "Goal-Oriented Requirements Engineering: An Overview of the Current Research," Department of Computer Science University Of Toronto, 2005.

[4] Martin S., "Promap Framework," 2010

[5] T. Rippl, "Business process modelling -methodsand methodologies," SYSTÉMOVÁ INTEGRACE, 2005.

[6] M. Koubarakis, et al., "A formal framework for business process modeling and design," Information Systems, vol. 27, pp. 299-319, 2002.

[7] F. R. Lin, et al., "A generic structure for businessprocess modeling," Business Process Management Journal, vol/issue: 8(1), pp. 19-4, 2002.

[8] A. V. Lamsweerde, "Requirements Engineering, From System Goal to UML Models to Software Specification," John Wiley \& Sons Ltd, 2009.

[9] A. Hallerbach, "Capturing Variability in Business Process Models: The Provop Approach".

[10] A. N. Fajar, et al., "System Architecture in the Dynamic Environment Based on Commonality and Variability Business Processes," 8thICCM, Seoul, 2012.

[11] A. Vaisman, "An Introduction to Business Process Modeling," Department of Computer \& Decision Engineering (CoDE) Université Libre de Bruxelles, BI Summer School, 2012.

[12] R. Bonif' acio and P. Borba, "Modeling scenario variability as crosscutting mechanisms," in Proc. of AOSD '09, ACM, pp. 125-136, 2009.

[13] E. K. Budiardjo, et al., "ZEF Framework for e-government applications: Featuring SOA \& BPM Allignment," IJCTE, vol/issue: 5(2), 2012. 
[14] A. N. Fajar, et al., "R2FM Method for Requirement Analysis in Software Product Line for E-Government Applications," IPCT, Rhome, Italy, 2014.

[15] A. N. Fajar and I. M. Shofi, "Conceptual Methodology for Requirement Engineering Based on GORE and BPM," IC- ITECHS, 2014. ISSN 2356-4407.

[16] Z. Shang, "Research on Adaptation of Service-based Business Processes," TELKOMNIKA Indonesian Journal of Electrical Engineering, vol/issue: 12(1), pp. $442 \sim 44,2014$.

[17] Y. Oh and T. Obi, "Identifying Phishing Threats in Government Web Services," International Journal of Information \& Network Security, vol/issue: 2(1), pp. 32 42, 2013.

\section{BIOGRAPHIES OF AUTHORS}

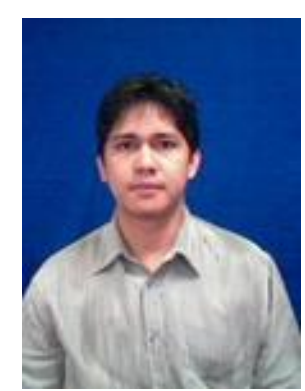

Dr. Ahmad Nurul Fajar,.Doctore in Computer Science, graduated from Faculty of ComputerScience University of Indonesia (UI) in 2014. In 2001, he is graduated from Gunadarma University majoring in Informatics. Master of Science Informatics was completed in 2004 at Bandung Institute of Technology (ITB). Currently, he is the Faculty Member of Binus Graduate Program, Department of Master of Information System. His email is afajar@binus.edu, ahamdnurulfajar@gmail.com.

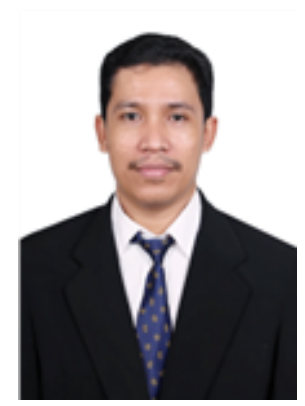

Dr. Imam Marzuki Shofi. Doctore in Computer Science, Faculty of ComputerScience University of Indonesia (UI). Bachelor Degree from Mathematics Diponegoro University and Master of Science Informatics was completed at Bandung Institute of Technology (ITB). Currently, he is the Faculty Member of Informatics Engineering Department UIN Syarif Hidayatullah Jakarta. His email is imam@uinjkt.ac.id,imam_shofi@yahoo.com. 